\title{
Pregnancy outcomes in women with Budd-Chiari syndrome or portal vein thrombosis - A multicentre retrospective cohort study
}

\author{
Hanke Wiegers ${ }^{1}$, Eva N. Hamulyák ${ }^{1}$, Stefanie E. Damhuis ${ }^{1}$, Jack R. Duuren ${ }^{1}$, Sarwa \\ Darwish Murad $^{2}$, Luuk J.J. Scheres ${ }^{3}$, Sanne Gordijn ${ }^{4}$, Jenneke Leentjens ${ }^{3}$, Johannes \\ Duvekot $^{2}$, Mandy N. Lauw ${ }^{2}$, Barbara Hutten ${ }^{1}$, Saskia Middeldorp ${ }^{3}$, and Wessel \\ Ganzevoort ${ }^{5}$
}

\author{
${ }^{1}$ Amsterdam UMC Locatie AMC \\ ${ }^{2}$ Erasmus MC \\ ${ }^{3}$ Radboudumc \\ ${ }^{4} \mathrm{UMCG}$ \\ ${ }^{5}$ Academic Medical Center
}

May 17, 2021

\begin{abstract}
Objective: to evaluate current practice and outcomes of pregnancy in women previously diagnosed with Budd-Chiari syndrome and/or portal vein thrombosis, with and without concomitant portal hypertension. Design and setting: multicentre retrospective cohort study between 2008-2021 Population: Women who conceived in the predefined period after the diagnosis of Budd-Chiari syndrome and/or portal vein thrombosis Methods and main outcome measures: We collected data on diagnosis and clinical features. The primary outcomes were maternal mortality and live birth rate. Secondary outcomes included maternal, neonatal and obstetric complications. Results: Forty-five women (12 Budd-Chiari syndrome, 33 portal vein thrombosis; 76 pregnancies) were included. Underlying prothrombotic disorders were present in 23 of 45 women (51\%). Thirty-eight women (84\%) received low-molecular-weight heparin during pregnancy. Of 45 first pregnancies, 11 (24\%) ended in pregnancy loss and 34 (76\%) resulted in live birth of which 27 at term age ( $79 \%$ of live births and $60 \%$ of pregnancies). No maternal deaths were observed, one woman developed pulmonary embolism during pregnancy and two women (4\%) had variceal bleeding requiring intervention. Conclusions: The high number of term live births (79\%) and lower than expected risk of pregnancy-related maternal and neonatal morbidity in our cohort suggest that Budd-Chiari syndrome and/or portal vein thrombosis should not be considered as an absolute contra-indication for pregnancy. Individualized, nuanced counselling and a multidisciplinary pregnancy surveillance approach are essential in this patient population.
\end{abstract}

\section{Hosted file}

Manuscript_PregnancyOutcomesBuddChiari_V3_14may_revision.pdf available at https://authorea. com/users/414210/articles/522317-pregnancy-outcomes-in-women-with-budd-chiari-syndromeor-portal-vein-thrombosis-a-multicentre-retrospective-cohort-study

\section{Hosted file}

Tables_PregnancyOutcomesBuddChiari_V3_14May2021_revision.pdf available at https://authorea. com/users/414210/articles/522317-pregnancy-outcomes-in-women-with-budd-chiari-syndromeor-portal-vein-thrombosis-a-multicentre-retrospective-cohort-study

\section{Hosted file}


Supplemental tables_PregnancyOutcomesBuddChiari_V3_14May2021.pdf available at https: //authorea.com/users/414210/articles/522317-pregnancy-outcomes-in-women-with-buddchiari-syndrome-or-portal-vein-thrombosis-a-multicentre-retrospective-cohort-study

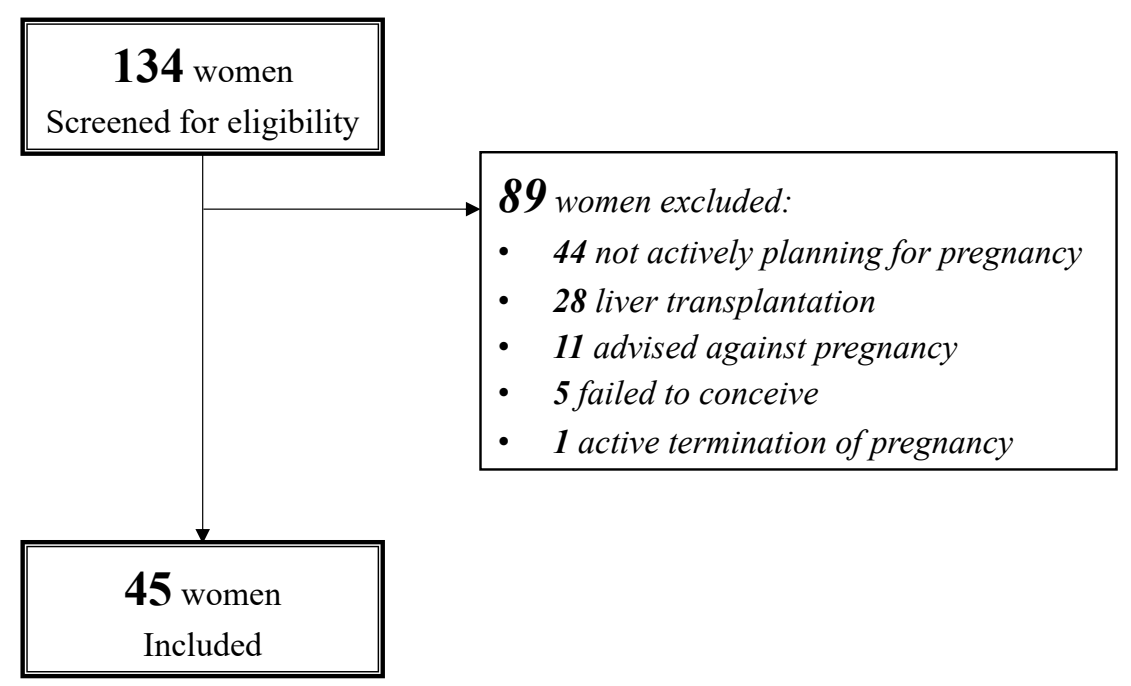

